Check for updates

Cite this: RSC Adv., 2019, 9, 25048

Received 25th January 2019

Accepted 5th August 2019

DOI: $10.1039 / c 9 r a 00664 h$

rsc.li/rsc-advances

\section{Cell changes and differential proteomic analysis during biodegradation of decabromodiphenyl ether (BDE-209) by Pseudomonas aeruginosa}

\author{
Yu Liu, abc Zhe Liu, ${ }^{\text {ab }}$ Aijun Gong, (D) *ab Lina Qiu, ${ }^{\text {ab }}$ Weiwei Zhang, ${ }^{\text {ab }}$ Jingrui Li, ${ }^{\text {ab }}$ \\ Fukai Li, ${ }^{\text {ab }}$ Yuzhen Bai, ${ }^{\text {ab }}$ Jiandi $\mathrm{Li}^{\mathrm{ab}}$ and Ge Gao ${ }^{\mathrm{ab}}$
}

\begin{abstract}
Decabromodiphenyl ether (BDE-209) is a brominated flame retardant widely used in the world which, being an emerging persistent organic pollutant, poses a great potential hazard to both human health and the ecological environment. Microbial biodegradation has been considered as an effective and environment-friendly technique to remediate BDE-209. Pseudomonas aeruginosa, a Gram-negative bacterium capable of degrading BDE-209, was isolated from PBDEs-contaminated soil. To promote microbial biodegradation of BDE-209 and gain further insight into its mechanism, cell changes and differential proteomic analysis of $P$. aeruginosa during biodegradation were studied. The results showed that high cell surface hydrophobicity of $P$. aeruginosa make the bacteria absorb BDE-209 more easily. The increase in cell membrane permeability was caused by the $P$. aeruginosa responding to BDE-209 stress. IR spectra showed that hydroxyl, amide and $\mathrm{CH}_{2}$ groups in the $P$. aeruginosa cell surface were involved in the interactions between BDE-209 with P. aeruginosa. The apoptotic-like cell changes and cell surface morphology changes were observed by flow cytometry (FCM) and field emission scanning electron microscopy (FESEM), respectively. Differentially expressed protein was analysed by two-dimensional electrophoresis (2-DE) and 40 protein spots were identified to be different after 5 days biodegradation.
\end{abstract}

\section{Introduction}

Polybrominated diphenyl ethers (PBDEs), a class of brominated flame retardants (BFRs), are widely used as flame retardants in a variety of consumer products, such as plastics, textiles, electronic goods and construction materials. ${ }^{1}$ There are three major commercial formulations of PBDEs, which differ in the degree of bromination: penta-BDE, octaBDE and deca-BDE. ${ }^{2}$ Penta-BDE and octa-BDE were banned under the Stockholm Convention in 2009. Deca-BDE (mainly BDE-209) was phased out in Europe and completely banned in the US in 2013. However, it is still produced and used in large quantities in some parts of the world. ${ }^{3,4}$ Due to the widespread use, chemical persistence and bioaccumulation, BDE-209 has been detected as the predominant BDE congener in atmosphere, water, soil, sediment, dust, especially in biota and humans, and its level has been increasing

${ }^{a}$ School of Chemistry and Biological Engineering, University of Science and Technology Beijing, Beijing 100083, China. E-mail: gongaijun5661@ustb.edu.cn; Fax: +86-1082375661; Tel: $+86-10-82375661$

${ }^{b}$ Beijing Key Laboratory for Science and Application of Functional Molecular and Crystalline Materials, University of Science and Technology Beijing, Beijing 100083, China

'Institute of Biotechnology, Daqing Branch of Heilongjiang Academy of Science, Daqing 163319, China since 1970s. ${ }^{5}$ Many toxicological studies have demonstrated that exposure to BDE-209 can lead to neurobehavioral toxicity, thyroid hormone disruption, cancer and reproductive toxicity. ${ }^{6}$ Therefore ongoing human exposure to BDE-209 may cause a potential risk to human health, and there is an urgent need to develop efficient methods for degrading and eliminating BDE-209.

Photolytic degradation, zerovalent iron (ZVI) degradation, and biodegradation are currently the major BDE-209 degradation methods. ${ }^{7}$ Biodegradation have gained much attention due to its being environment-friendly and low-cost. Recent studies on biodegradation of BDE-209 using microbes mostly focus on detecting degradation characteristics and proposing degradation pathways, ${ }^{8,9}$ but cell changes and differential proteomic analysis during biodegradation of BDE-209 are still unclear and deserve further investigation. Pseudomonas aeruginosa (P. aeruginosa), well capable of degrading BDE-209, could be used in bioremediation of the increasingly serious BDE-209-contamination. In the previous studies, Shi et al. reported the effect of cadmium ion on cell surface hydrophobicity (CSH) and membrane permeability variation during BDE-209 biodegradation by Pseudomonas aeruginosa. Results showed that direct adherence to the cell surface is the first step in biodegradation process, ${ }^{10}$ but no other changes of cell surface have been reported so far. Moreover, we have reported the biodegradation of BDE-209 by crude enzyme extracted 
from $P$. aeruginosa. Our results suggested that enzyme actually play the key role in the biodegradation process, ${ }^{\mathbf{1 1}}$ but it is unknown which kind of enzyme is responsible for the BDE-209 degradation. Up to now, differentially expressed protein in $P$. aeruginosa cell during biodegradation of BDE-209 have never been reported.

In this work, to better understand the mechanism of BDE209 biodegradation in cell level, $P$. aeruginosa cell changes were examined by focusing on cell activity, cell surface hydrophobicity, cell membrane permeability, cell surface functional group and morphology. Moreover, differentially expressed protein during the biodegradation of BDE-209 by $P$. aeruginosa was also investigated.

\section{Materials and experiments}

\subsection{Chemicals}

Decabromodiphenyl ether (BDE-209, >99\% purity) was purchased from Alfa Aesar (Tianjin, China). The single standard of BDE-209 was purchased from Sigma (St. Louis, USA). All other reagents were analytical grade and purchased from Sinopharm Chemical Reagent Beijing Co., Ltd (Beijing, China).

\subsection{Bacterial strain cultivation}

Pseudomonas aeruginosa ( $P$. aeruginosa) was previously isolated from PBDEs-contaminated soil in China, and preserved by our laboratory. $P$. aeruginosa was enriched in $50 \mathrm{~mL}$ of beef extract peptone medium on a rotary shaker at $200 \mathrm{rpm}$ and $30^{\circ} \mathrm{C}$ for $30 \mathrm{~h}$, followed by centrifugation at $8000 \mathrm{~g}$ for $10 \mathrm{~min}$ at $4{ }^{\circ} \mathrm{C}$. The harvested live cells were washed, resuspended, and cultivated in the mineral salt medium (MSM) with $20 \mathrm{mg} \mathrm{L}^{-1} \mathrm{BDE}-209$ on a rotary shaker at $200 \mathrm{rpm}$ and $35^{\circ} \mathrm{C}$.

The compositions of the beef extract peptone medium and the MSM medium were same as described in our previous research. $^{\mathbf{1 1}}$

\subsection{BDE-209 biodegradation experiments}

All BDE-209 biodegradation experiments were conducted in batch with $500 \mathrm{~mL}$ Erlenmeyer flasks. In each case, $6.0 \mathrm{mg}$ BDE209 and $300 \mathrm{~mL}$ MSM were added into a flask and mixed ultrasonically for $15 \mathrm{~min}$ to get a suspension. Afterwards, $120 \mathrm{mg}$ live $P$. aeruginosa was transferred to the suspension and cultured on a rotary shaker at $200 \mathrm{rpm}$ and $35{ }^{\circ} \mathrm{C}$ for 7 days. It was appropriate to keep cell density around $1 \times 10^{8}$ cells per $\mathrm{mL}$. As for the control, dead $P$. aeruginosa instead of live cells was used. At the degradation time of $0,1,3,5,7$ days, the quantification of BDE-209 was determined by using a gas chromatograph-mass spectrometer (GC-MS). BDE-209 degradation efficiency was calculated using the following equation:

$$
\text { Degradation efficiency }(\%)=\left(1-C_{1} / C_{0}\right) \times 100 \text {, }
$$

where $C_{0}$ and $C_{1}$ were the initial and residual BDE-209 concentration, respectively.

\subsection{Flow cytometry (FCM) analysis}

$P$. aeruginosa cells cultivated in MSM containing $20 \mathrm{mg} \mathrm{L}^{-1}$ BDE-209 at different biodegradation time were harvested by centrifugation and washed twice with PBS buffer ( $\mathrm{pH} 7.0)$, then re-suspended in $200 \mu \mathrm{L}$ binding buffer with $5 \mu \mathrm{L}$ Annexin V-FITC and $10 \mu \mathrm{L}$ PI. The mixture was incubated in the dark at room temperature for $20 \mathrm{~min}$ to allow for complete staining. Live, apoptotic, and dead cell populations were analyzed by flow cytometry (BD FACSCalibur), and data were analyzed using FlowJo software (v10.0.7). The control was conducted under same condition but in the absence of BDE-209.

\subsection{Cell surface characteristics analysis}

2.5.1 Cell surface hydrophobicity (CSH). Cell surface hydrophobicity (CSH) was determined using the modified method of microbial adhesion to hydrocarbons (MATH). ${ }^{12} P$. aeruginosa cells cultivated in MSM containing $20 \mathrm{mg} \mathrm{L}^{-1}$ BDE-209 at different degradation time were harvested, washed twice and re-suspended in PBS buffer $(\mathrm{pH} 7.0)$ to give an optical density of 0.5 at $600 \mathrm{~nm}\left(A_{0}\right) .1 \mathrm{~mL}$ of xylene was added to $3 \mathrm{~mL}$ of cell suspension, vortexed for $2 \mathrm{~min}$ and incubated for an additional $20 \mathrm{~min}$ at room temperature. Finally, the aqueous phase was removed and its optical density at $600 \mathrm{~nm}\left(A_{1}\right)$ was measured. $\mathrm{CSH}$ was calculated using the formula: $\mathrm{CSH}(\%)=\left(1-A_{1} / A_{0}\right) \times 100$. The control was conducted under same condition but in the absence of BDE-209.

2.5.2 Cell membrane permeability. Cell membrane permeability of $P$. aeruginosa was evaluated by measuring the release of $\beta$-galactosidase activity into the culture medium using $o$-nitrophenyl- $\beta$-D-galactopyranoside (ONPG) as a substrate. ${ }^{13}$ Pre-cultivated bacteria was pipetted into Erlenmeyer flasks containing $100 \mathrm{~mL}$ MSM and 1\% lactose, and incubated on a rotary shaker at $35{ }^{\circ} \mathrm{C}$ for $10 \mathrm{~h}$. Then the solutions were centrifuged at $8000 \mathrm{~g}$ for $5 \mathrm{~min}$, washed three times and re-suspended in $\beta$-galactosidase buffer. To the buffer was added BDE-209 at $20 \mathrm{mg} \mathrm{L}^{-1}$ then mixed with ONPG at $1 \mathrm{mg} \mathrm{mL}{ }^{-1}$. The control was conducted in the solution without BDE-209. Cell membrane permeability was measured by UV-spectrophotometer at $405 \mathrm{~nm}$.

2.5.3 Fourier transform infrared spectroscopy (FTIR). FTIR was used to characterize the cell surface functional groups of $P$. aeruginosa. $P$. aeruginosa cells cultivated in MSM containing $20 \mathrm{mg} \mathrm{L}{ }^{-1}$ BDE-209 at different degradation time were harvested, washed twice with MSM and dried in a freeze drier at $-50{ }^{\circ} \mathrm{C}$ for $30 \mathrm{~h}$. Samples were scanned in the $4000-400 \mathrm{~cm}^{-1}$ region using a FTIR spectrometer (Nicolet iS10, Thermo Fisher, USA). The control was conducted under same condition but in the absence of BDE-209.

2.5.4 Field emission scanning electron microscopy (FESEM). Surface morphology of $P$. aeruginosa was observed under a FESEM (SU8010, Hitachi, Japan). P. aeruginosa cells cultivated in MSM containing $20 \mathrm{mg} \mathrm{L}^{-1}$ BDE-209 at different degradation time were harvested and subjected to a series of pre-treatment processes including washing with 
PBS, fixation with glutaraldehyde, gradient dehydration with water-ethanol solutions, replacement with tertiary butyl alcohol and freeze drying. Finally, the dried samples were mounted on a conducting resin and sputter-coated with gold prior to the FESEM analysis. The control was conducted under same condition but in the absence of BDE209.

\subsection{Differentially expressed protein analysis}

$P$. aeruginosa cultured for 5 days in MSM with or without BDE$209\left(20 \mathrm{mg} \mathrm{L}^{-1}\right)$ were harvested by centrifugation at $6000 \mathrm{~g}$ and $4{ }^{\circ} \mathrm{C}$ for $15 \mathrm{~min}$ and washed three times with cold PBS. The cell pellet was resuspended in the lysis buffer, and then cells were disrupted by sonication in an ice bath. The protein extracts underwent ultracentrifugation for $45 \mathrm{~min}$ at $12000 \mathrm{~g}$ and $4{ }^{\circ} \mathrm{C}$. Afterwards, the obtained supernatants were purified using 2-D Clean-Up Kit (Amersham Biosciences, USA) and the protein concentration was determined by 2-D Quant Kit (Amersham Biosciences, USA) with bovine serum albumin as a standard. Two-dimensional electrophoresis (2-DE) was performed based on the method described by Liu et al. ${ }^{14}$ For the first dimension, isoelectric focusing (IEF), $500 \mu \mathrm{g}$ of protein was loaded onto an immobilized pH gradient (IPG) strip ( $24 \mathrm{~cm}, \mathrm{pH} 4-7$ ). After IEF separation, the IPG strips were equilibrated in two equilibration buffer for $15 \mathrm{~min}$ as described by Song et al. ${ }^{15}$ Then the proteins were further separated on $\mathbf{1 2 . 5 \%}$ SDS-polyacrylamide gels for the second dimension. After the completion of 2-DE, gels were stained with Coomassie brilliant blue, scanned using ImageScanner III (GE Healthcare) and analyzed with ImageMaster 2D Platinum software (Version 7.0, GE Healthcare). Altered abundances of spots were standardized and then compared based on their volume percentages in the total spot volume over the whole gel image. Significantly changed spots were selected by the rate increased/decreased $\geq 2$-fold or complete appearance and disappearance. Differential expressed proteins were excised from the gels and digested with trypsin and analyzed by a 4800 Plus MALDI TOF/TOF mass spectrometer (Applied Biosystems, Foster City, USA). Both the MS and MS/MS data were integrated and processed using the GPS Explorer V3.6 software (Applied Biosystems, USA) and searched against the NCBI database using Mascot V2.1 software (Matrix Science, UK). Protein scores greater than 65 were significant and accepted.

\subsection{Extraction and analytical methods}

For the extraction procedure, we refer to previous work. ${ }^{\mathbf{1 1}}$ The analytical method for BDE-209 was the same as in the literature $^{\mathbf{1 6}}$ and analysis by 7890-5975c GC-MS (Agilent, USA) equipped with a DB-5 MS column $(60 \mathrm{~m} \times 0.25 \mathrm{~mm} \times 0.25 \mu \mathrm{m})$. The quantification was performed with a five-point standard curve of BDE-209.

\subsection{Quality assurance and quality control}

All experiments were performed in triplicate and the mean values were given. The standard deviations ranged from $1.0 \%$ to $5.0 \%$.

\section{Results}

\subsection{BDE-209 biodegradation by $P$. aeruginosa}

Fig. 1 shows the degradation efficiency of BDE-209 by P. aeruginosa during biodegradation time. As shown, the degradation efficiency of BDE-209 rose slowly in day 1 and then ascended sharply from day 3 , finally levelled off after 5 days. This trend was in accordance with Shi's work, ${ }^{\mathbf{1 0}}$ but changes in cellular properties during the biodegradation of BDE-209 by $P$. aeruginosa were not discussed deeply. Hence, in the following, we focused on cell changes of $P$. aeruginosa during degradation time.

\subsection{Apoptotic-like cell changes of $P$. aeruginosa during BDE- 209 biodegradation}

To quantitatively gain insight into apoptotic-like cell changes of P. aeruginosa during BDE-209 biodegradation, a display of PI versus Annexin V-FITC fluorescence was measured by FCM analysis (Fig. 2). As shown in Fig. 2, four groups of cells were clearly seen in each acquired data plot: dead cells (Q1, positive for PI and negative for Annexin V-FITC), late apoptotic cells (Q2, positive for PI and Annexin V-FITC), live cells (Q3, negative for PI and Annexin V-FITC), early apoptotic cells (Q4, negative for PI and positive for Annexin V-FITC). From the results it can be observed, $P$. aeruginosa cells treated with $20 \mathrm{mg} \mathrm{L}^{-1}$ BDE-209 in day 1 and day 7 exhibited an increase of apoptosis and death compared to day 0 . The total apoptosis rate first increased to $1.17 \%$ in the day 1 as compared to that in day $0(0.22 \%)$, then declined in day 3 and day 5 , finally increased to $2.63 \%$ in day 7 . Moreover, cells treated with BDE-209 showed the highest population of dead cells (5.84\%) in day 1 . For P. aeruginosa cells in control, cell death increased in day $1(3.23 \%)$ and day $3(4.11 \%)$, then cell apoptosis began to increase from day $5(0.46 \%)$, and reached $1.97 \%$ in day 7 .

\subsection{Cell surface changes during BDE-209 biodegradation}

3.3.1 Changes in CSH and cell membrane permeability. Fig. 3 shows the changes of $\mathrm{CSH}$ and cell membrane

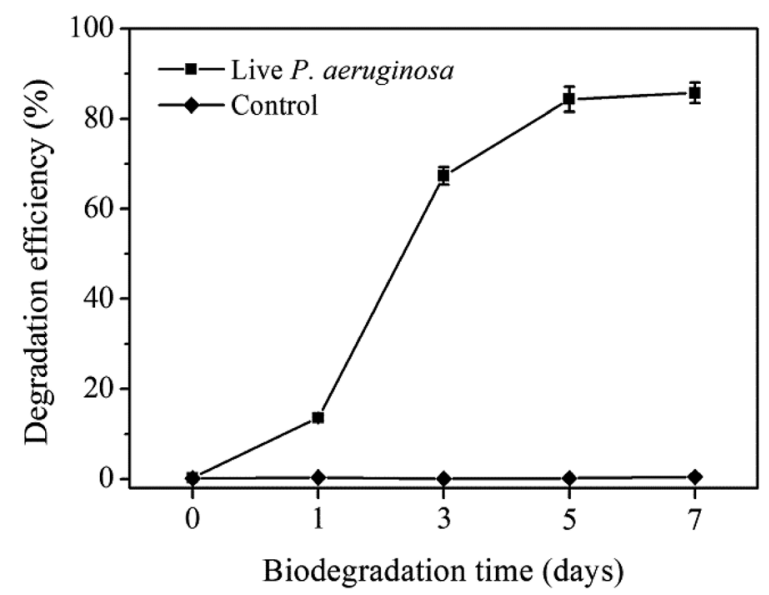

Fig. 1 Degradation efficiency of $20 \mathrm{mg} \mathrm{L}^{-1}$ BDE-209 under incubation time. 

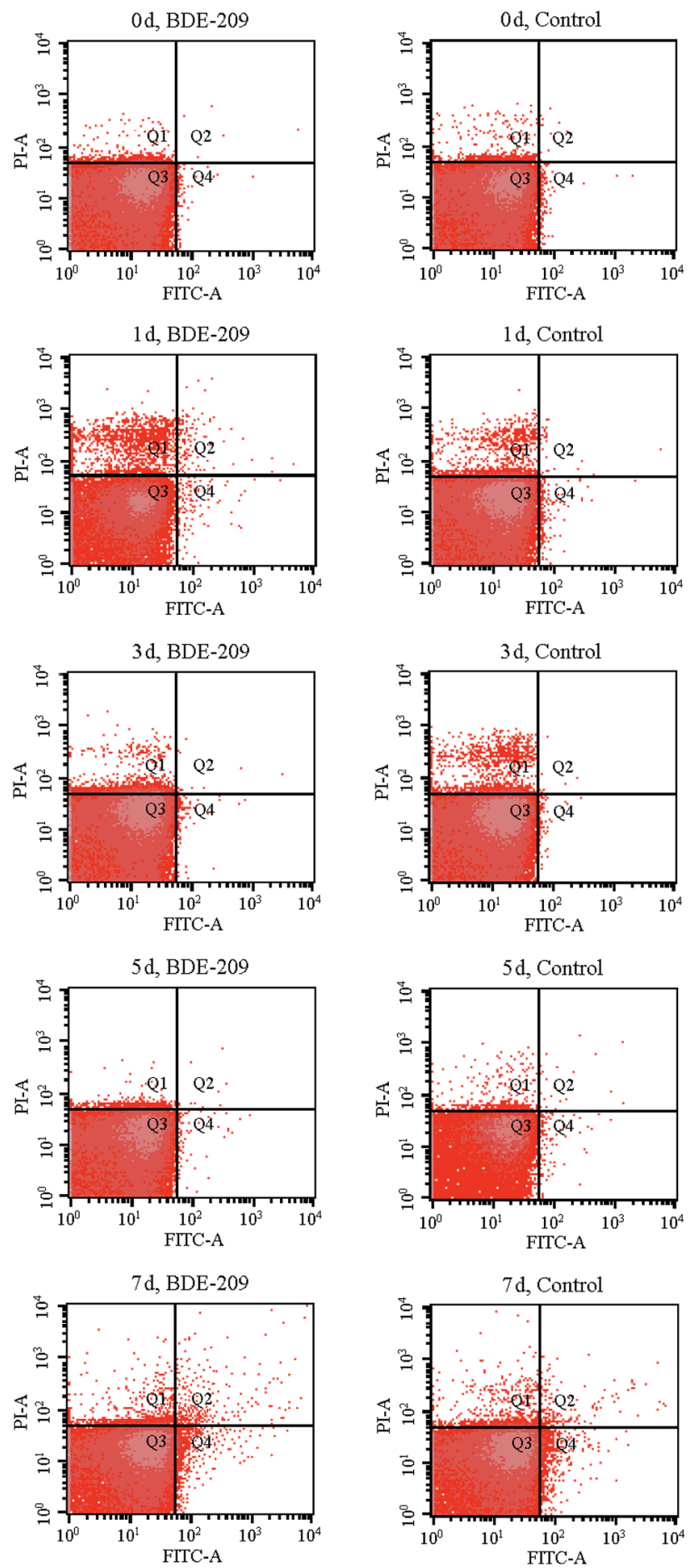

Fig. 2 Apoptotic-like cell changes of $P$. aeruginosa after treatment with $20 \mathrm{mg} \mathrm{L}^{-1} \mathrm{BDE}-209$ and without BDE-209 (control) for 0-7 days. Four quadrants (Q) are representing: (Q1) dead cells; (Q2) late apoptotic cells; (Q3) live cells; (Q4) early apoptotic cells.

permeability of $P$. aeruginosa treated with and without BDE-209. In the presence of $\mathrm{BDE}-209$, the $\mathrm{CSH}$ first maintained at high level from $48.3 \%$ to $52.1 \%$ until day 3 and then decreased markedly from the 5 th day. The cell membrane permeability increased gradually from day 1 to 3 then sharply from day 5 to 7 .
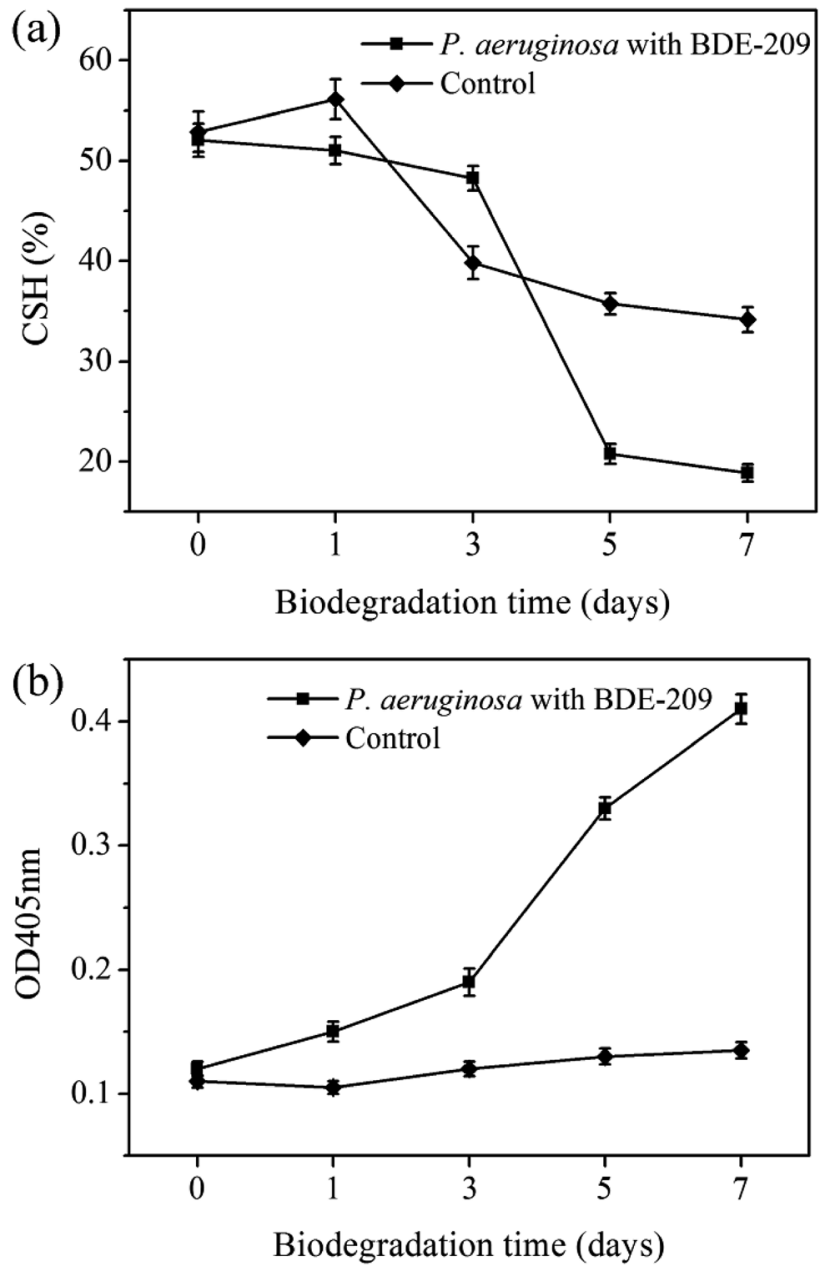

Fig. 3 Changes of $\mathrm{CSH}$ (a) and cell membrane permeability (b) of $P$. aeruginosa during BDE-209 biodegradation.

In the absence of BDE-209, both $\mathrm{CSH}$ and cell membrane permeability changes less obviously.

3.3.2 FTIR analysis. The functional groups present on the cell surface of $P$. aeruginosa during BDE-209 biodegradation were explored to reveal the cell surface changes through FTIR analysis as shown in Fig. 4. The peak assignments of $P$. aeruginosa were as follows: 1086 and $1236 \mathrm{~cm}^{-1}$ were ascribed to $\mathrm{P}=\mathrm{O}$ stretching vibration of phosphate groups, $1398 \mathrm{~cm}^{-1}$ ascribed to $\mathrm{C}-\mathrm{O}$ stretching vibration of $-\mathrm{COOH}, 1455 \mathrm{~cm}^{-1}$ ascribed to $\mathrm{C}-\mathrm{H}$ bending vibration of $-\mathrm{CH}_{2}, 1544 \mathrm{~cm}^{-1}$ ascribed to $\mathrm{N}-\mathrm{H}$ and $\mathrm{C}-\mathrm{N}$ in amide groups, 1651 and $1741 \mathrm{~cm}^{-1}$ ascribed to $\mathrm{C}=\mathrm{O}$ stretching vibration, 2925 and $2958 \mathrm{~cm}^{-1}$ ascribed to $\mathrm{C}-\mathrm{H}$ stretching vibration, $3296 \mathrm{~cm}^{-1}$ ascribed to $\mathrm{O}-\mathrm{H}$ stretching vibration. ${ }^{17}$ For $P$. aeruginosa cells treated with BDE-209, the peaks at 3296, 1651 and $1544 \mathrm{~cm}^{-1}$ become broader, and the intensity of peaks $2925 \mathrm{~cm}^{-1}$ decreased gradually. In control, less obvious changes with time were observed.

3.3.3 Changes in cell surface morphology. Fig. 5 revealed the changes of cell surface morphology in presence and absence of BDE-209. In the presence of BDE-209, $P$. 


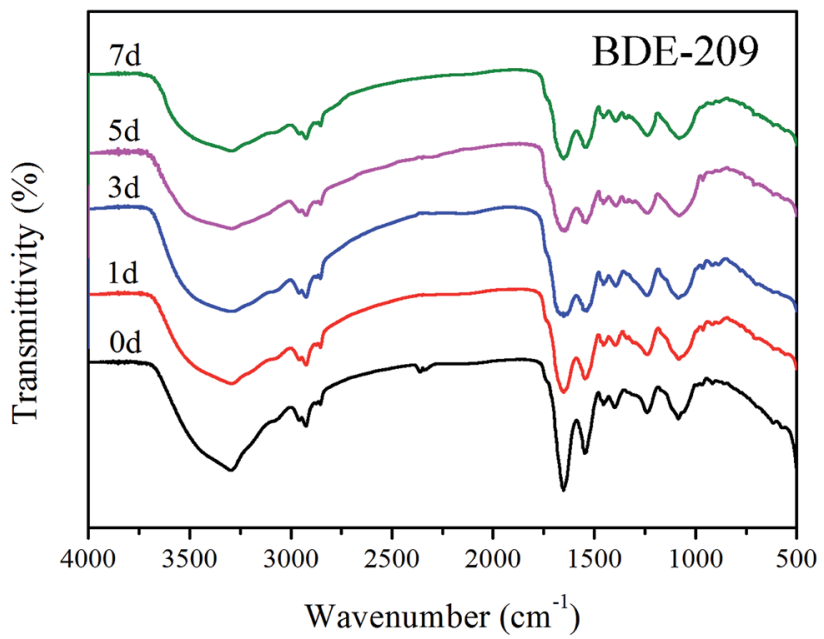

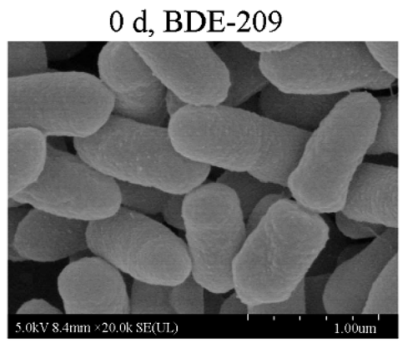

$1 \mathrm{~d}, \mathrm{BDE}-209$

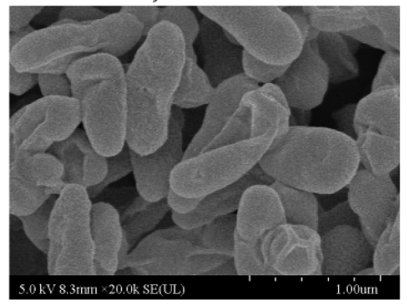

3 d, BDE-209

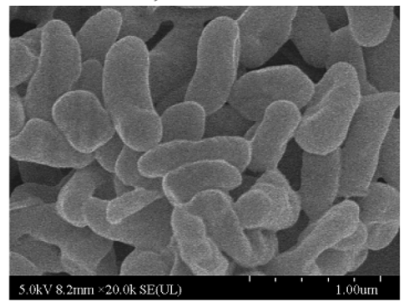

$5 \mathrm{~d}, \mathrm{BDE}-209$

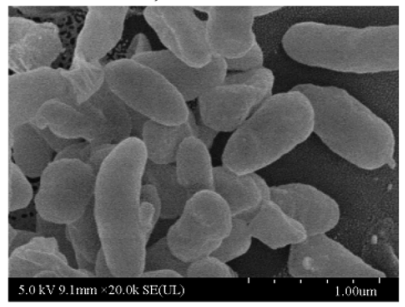

7 d, BDE-209

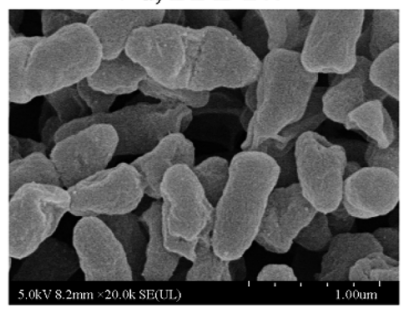

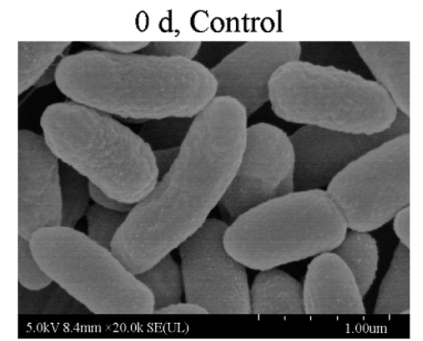

$1 \mathrm{~d}$, Control

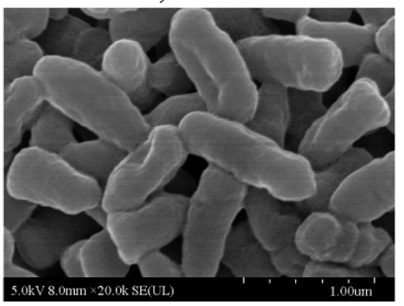

$3 \mathrm{~d}$, Control

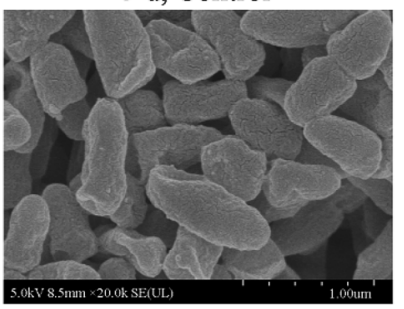

$5 \mathrm{~d}$, Control

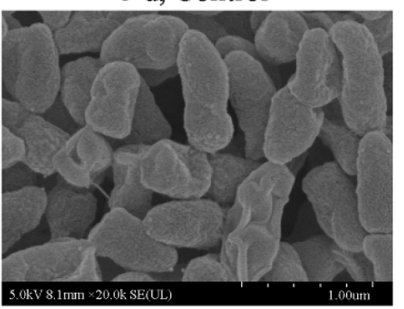

$7 \mathrm{~d}$, Control

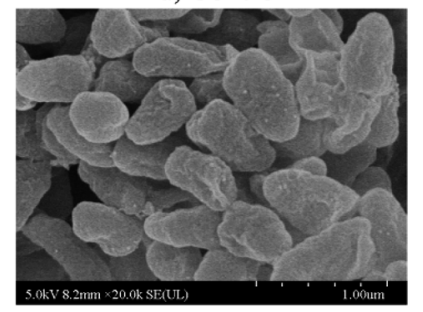

Fig. 5 FESEM images of the $P$. aeruginosa cells treated with $20 \mathrm{mg} \mathrm{L}^{-1}$ BDE-209 and without BDE-209 (control) at the degradation time of 0-7 days.

biodegradation. Out of them, seven protein spots in the same location of Fig. $6 a$ and $b$ exhibited significant changes at the level of protein expression, they were named as 1-7. Spots 811, and spots 12-40 were those spots that only appeared in Fig. $6 \mathrm{a}$ and b, respectively. The 40 spots were analysed by MALDI-TOF-TOF with a significant mascot score $>65$ ( $p$-value $<0.05$ ), among which 12 identified spots are shown in Table 1. Table 1 summarizes details of these identified proteins including their protein names, accession numbers and other MS data. 

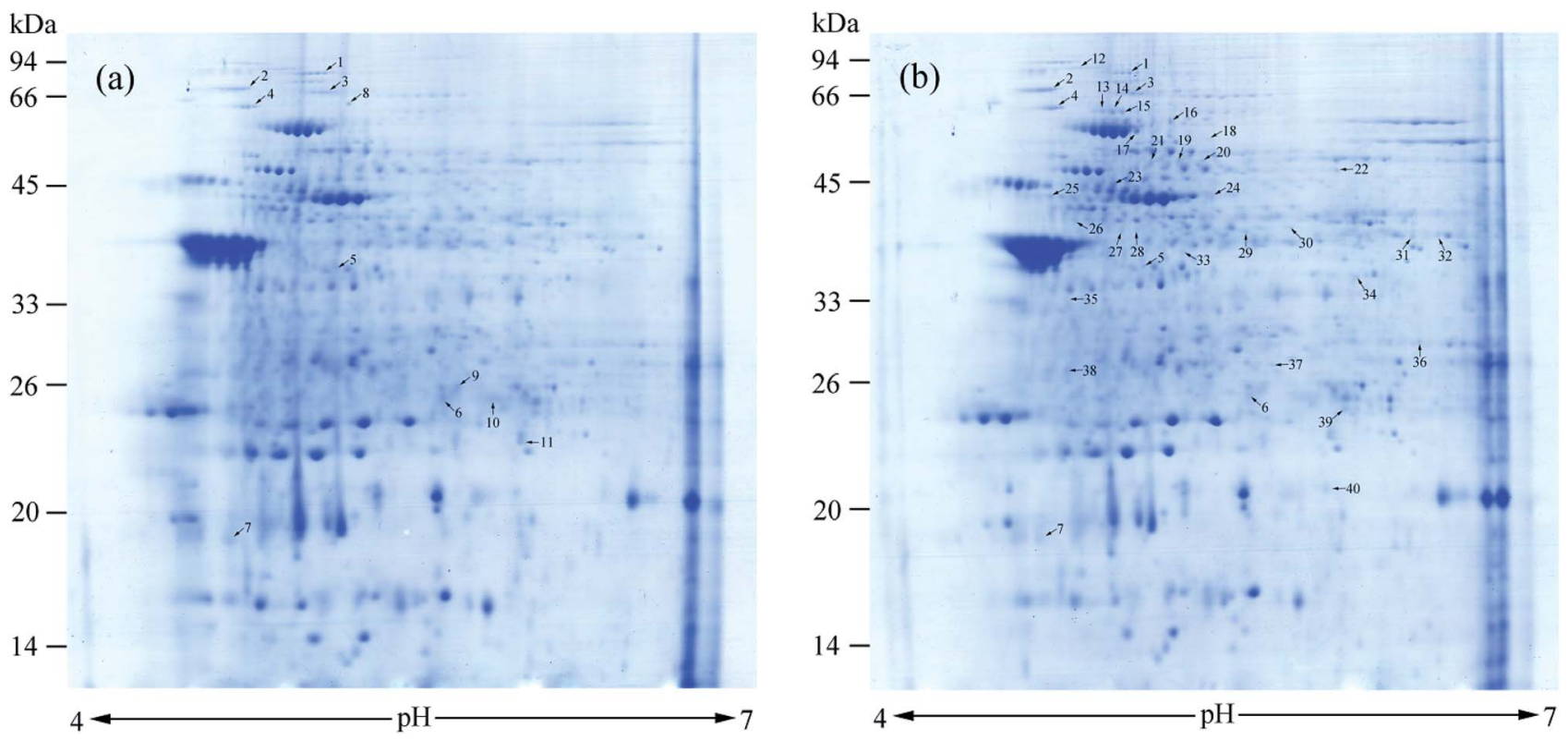

Fig. 6 Representative 2-DE gels of proteome from $P$. aeruginosa cultured in MSM without BDE-209 (a) and with 20 mg L ${ }^{-1}$ BDE-209 (b). The 40 differentially expressed proteins during BDE-209 biodegradation are marked by numbers on the gels, and were analyzed by MALDI-TOF/TOF mass spectrometry.

Table 1 List of protein spots which were differentially expressed in P. aeruginosa with $20 \mathrm{mg} \mathrm{L}^{-1}$ BDE-209 for 5 days

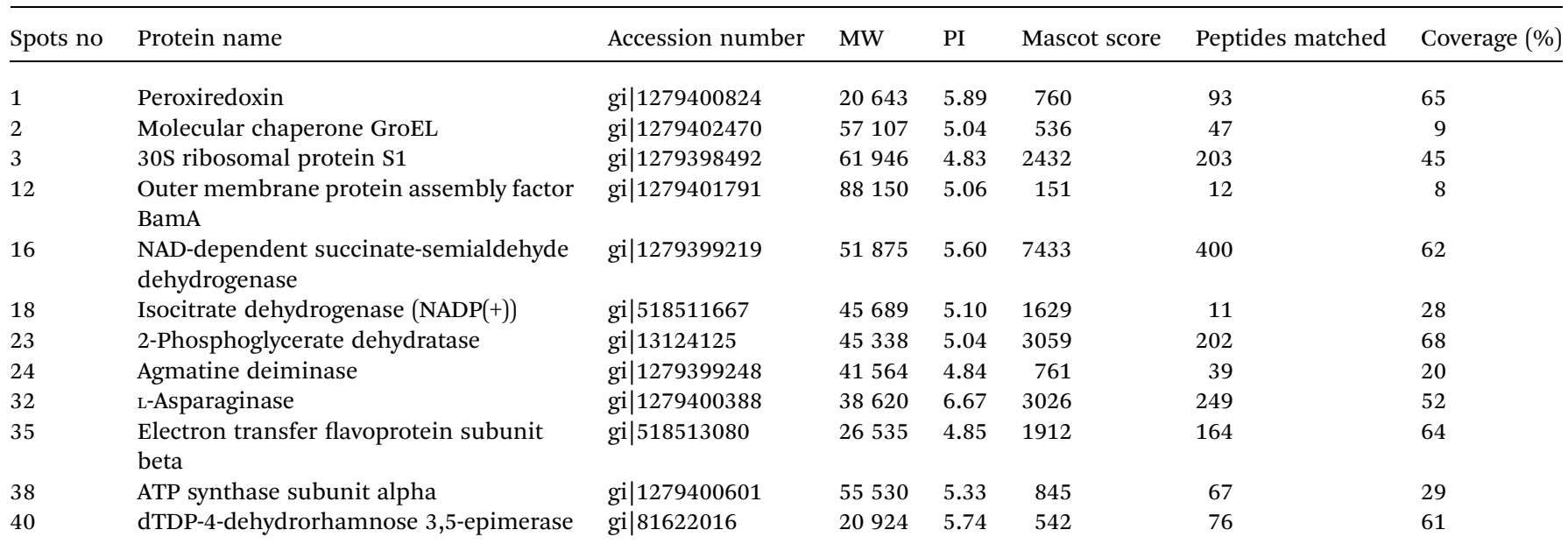

\section{Discussion}

In the biodegradation process of harmful and toxic organic contaminants, microbes resist organic contaminants at the beginning, and then the interaction between microbes and contaminants leads to a series of cellular characteristic changes. ${ }^{18}$ In this work, we have found that $P$. aeruginosa had a series of cellular characteristic changes during the biodegradation of BDE-209. When BDE-209 biodegradation had just began (day 0), P. aeruginosa treated with and without BDE-209 both grew well and had normal cell morphology. In day 1, BDE-209 degradation efficiency was low. Compared with control, $P$. aeruginosa treated with BDE-209 caused a larger population of apoptotic and dead cells, accompanied by the appearance of plicated and irregular shaped cells. Apoptosis is a form of programmed cell death (PCD) that is essential in eliminating old, unnecessary or damaged cells to maintain appropriate cell numbers and protect bacteria against poor environment. ${ }^{19,20}$ So this is probably because the initial exposure of $P$. aeruginosa to BDE-209 lead to resistance, some cells become deformed, and then apoptosis appears to protect bacteria against BDE-209 stress. ${ }^{21}$ In day 3 and 5, BDE-209 degradation efficiency increased apparently, apoptotic and dead cell decreased, cell morphology return to normal. This is probably because $P$. aeruginosa has adapted to BDE-209 gradually, followed by degrading BDE-209 as carbon source for metabolism. ${ }^{22}$ As for control, these changes were not observed. In day 7, no matter $P$. aeruginosa was treated with or without 
BDE-209, cell apoptosis and death appeared, and cells became rough and atrophic. This is probably because the quantity of nutrients in the culture medium declined and growing environment became unfavorable. ${ }^{23}$

One of most common mechanisms explains that hydrophobic BDE-209 first adheres to the hydrophobic regions of the cell surface, then enters the cell through cell membrane, finally is degraded by intracellular enzymes. ${ }^{24,25}$ For this reason, CSH and cell membrane permeability are the most important factors in determining whether BDE-209 can be successfully adsorbed onto the surface of cells and enter into the cells. In this experiment, we have found that $\mathrm{CSH}$ maintained at a high level till day 3, making P. aeruginosa adsorb hydrophobic BDE-209 more easily. Then $\mathrm{CSH}$ decreased markedly from day 5. Meanwhile, the cell membrane permeability increased gradually from day 1 then sharply from day 5 . The increase in cell membrane permeability was caused by the $P$. aeruginosa responding to BDE-209 stress. The membrane structure was changed due to the sharply increased cell membrane permeability and the hydrophobic regions was disrupted, which may be part of the reason for the decline of $\mathrm{CSH}$ of $P$. aeruginosa. ${ }^{20}$

$P$. aeruginosa is a Gram-negative bacterium. Its cell wall is mainly composed of polysaccharides, phospholipids and proteins, characteristic of carboxyl, phosphate, and amino groups, which can be assigned to in IR spectra (Fig. 4). ${ }^{26}$ During degradation, the changed peaks suggested that hydroxyl, amide and $\mathrm{CH}_{2}$ groups were involved in the interactions between BDE209 and $P$. aeruginosa. In control, these peaks did not change obviously with time. All the above results indicated that polysaccharides and proteins in the cell walls of $P$. aeruginosa may play critical roles in the binding of BDE-209. ${ }^{27}$

2-DE is an effective tool for gaining insight into physiological changes at cellular level. ${ }^{28}$ Thus analysis and identification of differentially expressed proteins during BDE-209 biodegradation could give us an insight into cell changes in this process. In this experiment, 12 differentially expressed proteins were identified and listed in Table 1. Peroxidase can degrade BDE-209, Li et al. found that manganese peroxidase plays an important role in BDE-209 depletion. ${ }^{29}$ 30S ribosomal protein S1, which can bind to a specific site of mRNA, starts protein synthesis. ${ }^{30}$ Electron transfer flavoprotein can transfer the electrons to the main respiratory chain. ${ }^{31}$ Outer membrane protein can form a stable folding intermediate, which keeps the Gram-negative bacterium survive under stress conditions. ${ }^{32}$ Molecular chaperone works to prevent outer membrane protein being adsorbed to outer membrane by capturing and stabilizing its folding intermediates. $^{33}$ Therefore, these enzymes help P. aeruginosa adapt to restricted BDE-209 conditions, reduce toxicity, and maintain the normal metabolism of cells. ${ }^{34}$ NAD-dependent succinatesemialdehyde dehydrogenase, isocitrate dehydrogenase and 2phosphoglycerate dehydratase were probably attributed to the resistance systems of $P$. aeruginosa to the oxidative stress induced by BDE-209. ${ }^{35}$ ATP synthase generates energy in the form of ATP, which was confirmed to play an important role in BDE biodegradation. ${ }^{36}$ The roles of agmatine deiminase, L-asparaginase and dTDP-4-dehydrorhamnose 3,5-epimerase in BDE-209 degradation is not known yet and further study is still needed.

\section{Conclusions}

Collectively, both cell surface and intracellular enzyme changes in the biodegradation of BDE-209 by $P$. aeruginosa. The apoptotic-like cell changes and cell surface morphology changes were observed during the biodegradation of BDE-209 by $P$. aeruginosa. The results showed that high $\mathrm{CSH}$ of $P$. aeruginosa facilitated the attachment of BDE-209 to cell surface. The increase in cell membrane permeability caused by $P$. aeruginosa responding to BDE-209 stress favored BDE-209 penetrating into cells and being degraded. IR spectra showed that polysaccharides and proteins in the cell walls of $P$. aeruginosa may participate in binding BDE-209. Differentially expressed protein was analysed through 2-DE, among which peroxidase and ATP synthase play a critical role in BDE-209 degradation. As far as we know, this is the first report on investigating cell changes and differentially expressed proteins during biodegradation of BDE209 by $P$. aeruginosa. These explorations offer new insights into the mechanism of BDE-209 biodegradation by P. aeruginosa.

\section{Conflicts of interest}

There are no conflicts to declare.

\section{Acknowledgements}

This work was financially supported by National Key R\&D Program of China (No. 2017YFF0106006) and Chinese National Natural Science Foundation (No. 51701016).

\section{References}

1 C. A. de Wit, Chemosphere, 2002, 46, 583-624.

2 R. Quiroz, L. Arellano, J. O. Grimalt and P. Fernandez, J. Chromatogr., A, 2008, 1192, 147-151.

3 A. Francois, R. Techer, M. Houde, P. Spear and J. Verreault, Environ. Toxicol. Chem., 2016, 35, 2215-2222.

4 H. W. Zhu, Y. Wang, X. W. Wang, T. G. Luan and N. F. Tam, Sci. Total Environ., 2014, 468-469, 130-139.

5 H. Stiborova, J. Vrkoslavova, P. Lovecka, J. Pulkrabova, P. Hradkova, J. Hajslova and K. Demnerova, Chemosphere, 2015, 118, 315-321.

6 M. Li, Z. Liu, L. Gu, R. Yin, H. Li, X. Zhang, T. Cao and C. Jiang, Front. Genet., 2014, 5, 1-6.

7 B. Z. Wu, Y. J. Sun, Y. H. Chen, H. K. Yak, J. J. Yu, W. S. Liao, K. H. Chiu and S. M. Peng, Chemosphere, 2016, 157, 115-123.

8 M. Lu, Z. Z. Zhang, X. J. Wu, Y. X. Xu, X. L. Su, M. Zhang and J. X. Wang, Bioresour. Technol., 2013, 149, 8-15.

9 G. Y. Xu and J. B. Wang, Chemosphere, 2014, 110, 70-77.

10 G. Y. Shi, H. Yin, J. S. Ye, H. Peng, J. Li and C. L. Luo, J. Hazard. Mater., 2013, 263, 711-717.

11 Y. Liu, A. J. Gong, L. N. Qiu, J. R. Li and F. K. Li, Int. J. Environ. Res. Public Health, 2015, 12, 11829-11847.

12 D. Y. Ren, C. Li, Y. Q. Qin, R. L. Yin, X. Li, M. Y. Tian, S. W. Du, H. H. Guo, C. X. Liu, N. Zhu, D. D. Sun, Y. Li and N. Y. Jin, Anaerobe, 2012, 18, 508-515. 
13 L. L. Wang, L. T. Tang, R. Wang, X. Y. Wang, J. S. Ye and Y. Long, Environ. Sci. Pollut. Res., 2016, 23, 5166-5178.

14 S. S. Liu, C. L. Guo, Z. Dang and X. J. Liang, Ecotoxicol. Environ. Saf., 2017, 137, 256-264.

15 Q. Q. Song, P. F. Zheng, L. G. Qiu, X. Jiang, H. W. Zhao, H. L. Zhou, Q. Han and X. P. Diao, Toxicol. Lett., 2016, 240, 185-195.

16 Y. Liu, A. J. Gong, L. N. Qiu, J. R. Li and F. K. Li, MicrobiologyOpen, 2017, 6, 1-10.

17 N. Bai, S. Wang, R. Abuduaini, M. N. Zhang, X. F. Zhu and Y. H. Zhao, Sci. Total Environ., 2017, 590-591, 343-351.

18 S. S. Liu, C. L. Guo, X. J. Liang, F. J. Wu and Z. Dang, Ecotoxicol. Environ. Saf., 2016, 129, 210-218.

19 N. Allocati, M. Masulli, C. Di Ilio and V. De Laurenzi, Cell Death Dis., 2015, 6, e1609.

20 S. Tang, H. Yin, S. Chen, H. Peng, J. Chang, Z. Liu and Z. Dang, J. Hazard. Mater., 2016, 308, 335-342.

21 M. C. Ferrante, G. M. Raso, E. Esposito, G. Bianco, A. Iacono, M. T. Clausi, P. Amero, A. Santoro, R. Simeoli, G. Autore and R. Meli, Toxicol. Lett., 2011, 202, 61-68.

22 L. L. Liu, Y. C. Zhang, R. H. Liu, Z. P. Wang, F. Xu, Y. L. Chen and K. F. Lin, Environ. Sci. Pollut. Res., 2016, 23, 3925-3933.

23 H. Lee and D. G. Lee, J. Microbiol. Biotechnol., 2019, 29, 10141021.

24 L. Shapiro, Cell, 1993, 73, 841-855.
25 Z. Wu, M. Xie, Y. Li, G. Gao, M. Bartlam and Y. Wang, Amb. Express, 2018, 8, 27.

26 S. Luo, L. L. Li, A. W. Chen, Q. R. Zeng, H. Xia and J. D. Gu, Chemosphere, 2017, 178, 187-196.

27 N. Bai, S. Wang, R. Abuduaini, M. Zhang, X. F. Zhu and Y. H. Zhao, Sci. Total Environ., 2017, 590, 343-351.

28 Z. W. Cheng, Z. Y. Chen, X. Yan, Y. W. Bian, X. Deng and Y. M. Yan, J. Proteomics, 2018, 170, 1-13.

29 X. Li, A. Y. Chen, Y. Wu, L. Wu, L. Xiang, H. M. Zhao, Q. Y. Cai, Y. W. Li, C. H. Mo, M. H. Wong and H. Li, Sci. Total Environ., 2018, 634, 417-426.

30 M. P. Kalapos, H. Paulus and N. Sarkar, Biochimie, 1997, 79, 493-502.

31 C. L. Hall and J. D. Lambeth, J. Biol. Chem., 1980, 255, 35913595.

32 K. Chourabi, F. Torrella, S. Kloula, J. A. Rodriguez, I. Trabelsi, S. Campoy, A. Landoulsi and A. Chatti, Arabian J. Geosci., 2017, 10, 1-7.

33 R. N. Reusch, FEBS J., 2012, 279, 894-909.

$34 \mathrm{~J} . \mathrm{Xu}, \mathrm{H} . \mathrm{Q}$. Wang and D. K. Kong, IOP Conf. Ser. Earth Environ. Sci., 2018, 111, 012032.

35 A. K. Felux, D. Spiteller, J. Klebensberger and D. Schleheck, Proc. Natl. Acad. Sci., 2015, 112, E4298-E4305.

36 M. Feng, H. Yin, H. Peng, X. T. Liu, P. P. Yang, G. N. Lu and Z. Dang, Ecotoxicol. Environ. Saf., 2017, 142, 388-398. 